\title{
Dynamic Urinary Proteome Changes in Ovalbumin-Induced Asthma Mouse Model Using Data-Independent Acquisition Proteomics
}

\author{
Weiwei Qin ${ }^{1,2}$ \\ Ting Wang ${ }^{2}$ \\ Guangwei Liu ${ }^{3}$ \\ Lixin Sun' \\ Wei $\mathrm{Han}^{4}$ \\ Youhe Gao ${ }^{2}$ \\ 'Department of Anesthesiology, Qingdao \\ Municipal Hospital, Qingdao University, \\ Qingdao, 26607I, People's Republic of \\ China; ${ }^{2}$ Department of Biochemistry and \\ Molecular Biology, Gene Engineering \\ Drug and Biotechnology Beijing Key \\ Laboratory, Beijing Normal University, \\ Beijing, 100875, People's Republic of \\ China; ${ }^{3}$ Key Laboratory of Cell \\ Proliferation and Regulation Biology, \\ Ministry of Education, Institute of Cell \\ Biology, College of Life Sciences, Beijing \\ Normal University, Beijing, 100875, \\ People's Republic of China; ${ }^{4}$ Department \\ of Respiratory Medicine, Qingdao \\ Municipal Hospital, Qingdao University, \\ Qingdao, 26607I, People's Republic of \\ China
}

Correspondence: Youhe Gao; Wei Han Tel +86 I0 58804382; +8653285937809 Email gaoyouhe@bnu.edu.cn; sallyhanI@I63.com
Background: In this work, we aim to investigate dynamic urinary proteome changes during asthma development and to identify potential urinary protein biomarkers for the diagnosis of asthma.

Methods: An ovalbumin (OVA)-induced mouse model was used to mimic asthma. The urinary proteome from asthma and control mice was determined using data-independent acquisition combined with high-resolution tandem mass spectrometry.

Results: Overall, 331 proteins were identified, among which 53 were differentially expressed (26, 24, 14 and 20 on days 2, 8, 15 and 18, respectively; 1.5-fold change, adjust $\mathrm{P}<0.05$ ). Gene Ontology annotation of the differential proteins showed that the acute-phase response, innate immune response, $\mathrm{B}$ cell receptor signaling pathway, and complement activation were significantly enriched. Protein-protein interaction network revealed that these differential proteins were partially biologically connected in OVA-induced asthma, as a group. On days 2 and 8, after two episodes of OVA sensitization, six differential proteins (CRAMP, ECP, HP, F2, AGP1, and CFB) were also reported to be closely associated with asthma. These proteins may hold the potential for the early screening of asthma. On days 15 and 18 , after challenged with 1\% OVA by inhalation, seven differential proteins (VDBP, HP, CTSE, PIGR, AAT, TRFE, and HPX) were also reported to be closely associated with asthma. Thus, these proteins hold the potential to be biomarkers for the diagnosis of asthma attack.

Conclusion: Our results indicate that the urinary proteome could reflect dynamic pathophysiological changes in asthma progression.

Keywords: OVA-induced asthma, mice, urine, proteome, data-independent acquisition

\section{Introduction}

Asthma is a heterogeneous disease that is usually characterized by chronic airway inflammation. It is characterized by variable symptoms, such as wheeze, dyspnea, and chest tightness and/or cough that vary over time and intensity, together with variable expiratory airflow limitation. ${ }^{1}$ Asthma is a major public health concern worldwide, with global prevalence ranging from $1 \%$ to $21 \%$ in adults $^{2}$ and up to $32 \%$ in children aged 6-7 years. ${ }^{3}$ The predominant mechanism involved in the pathogenesis of asthma is a Type 2 helper T cell (Th2) cytokine-mediated eosinophilic airway inflammation associated with hyper-responsiveness of the lungs. ${ }^{4}$ Asthma is a heterogeneous disease; many clinical phenotypes of asthma have been identified, including allergic and nonallergic asthma, late-onset asthma, 
asthma with persistent airflow limitation, and asthma with obesity. ${ }^{5,6}$ Many of these and other phenotypes of asthma are diagnosed based on the clinical characteristics.

Spirometry is by far the primary diagnostic approach for asthma, which reflects disease severity rather than disease activity. ${ }^{7}$ Moreover, its measurements strictly depend on patient's compliance, physician's expertise, and data interpretation. ${ }^{8}$ Especially for children aged under 6 years, the diagnosis is more difficult because they are too young to undergo spirometry. Besides, clinical symptoms on which pulmonologists rely for a correct diagnostic approach are subjective and nonspecific. The differential diagnosis in a patient with suspected asthma is based on the age of onset, reversibility of airflow limitation, symptom variability, and atopy. A significant proportion of patients with chronic respiratory symptoms (9$55 \%$ ) has diagnoses and/or features of both asthma and chronic obstructive pulmonary disease (COPD). ${ }^{9}$ Distinguishing asthma from chronic airflow limitation due to COPD becomes problematic, particularly among smokers. ${ }^{10,11}$ Thus, there is an urgent need for noninvasive biomarkers for early diagnosis, evaluation of lung functional impairment, and prognosis in asthma.

Mass spectrometry (MS)-based proteomics has dramatically improved and emerged as a prominent tool in the field of biomarker study. Many protein biomarkers of asthma and/or COPD have been described and categorized as primarily blood and bronchoalveolar lavage fluid (BALF) biomarkers. ${ }^{12,13}$ For example, MS-based proteomic analysis revealed serum ApoE to be significantly downregulated in atopic asthmatics compared to healthy volunteers. ${ }^{14}$ Comparative proteomics analysis of patients with quick development and slow development COPD, provided 15 potential serum biomarkers for efficiently predicting the development phenotypes of COPD. ${ }^{15}$

Urine, as an attractive resource for biomarker research, can be collected noninvasively and continuously, which has arrested more and more concerns. Mass spectrometrybased proteomics based on the association between different protein profiles and pathogenic processes is gaining an important role in pulmonary medicine. ${ }^{16-18}$ Urinary proteomic studies have identified several candidate biomarkers for pulmonary disease, such as lung cancer, ${ }^{19}$ pulmonary fibrosis, and tuberculosis. ${ }^{20,21}$ However, several candidate biomarkers of asthma have been described primarily in the sputum, blood, and bronchoalveolar lavage fluid. Besides, the urinary proteome could reflect changes in disease progression at the early stage. For example, the urinary proteome profiles changed significantly even in the absence of clinical manifestations or histopathological damage to the lung tissue in bleomycininduced pulmonary fibrosis ${ }^{21}$ and Walker-256 tail-vein injection-induced lung metastasis ${ }^{22}$ rat models. Therefore, urine can sensitively reflect pathophysiological changes in the lung tissue at an early stage and is, thus, a promising resource for studying the biomarkers of lung diseases.

This study aimed to observe dynamic urinary proteome changes during asthma development and to identify potential urinary protein biomarkers for the diagnosis of asthma. The data-independent acquisition (DIA) approach was used to profile the urinary proteome of OVA-induced asthma mouse model.

\section{Materials and Methods}

\section{Mice and Asthma Induction}

The C57BL/6J male mice (6-week-old) were purchased from Charles River (Beijing, China) and housed in light (12 h light: $12 \mathrm{~h}$ dark cycle) and temperature-controlled $\left(22 \pm 3^{\circ} \mathrm{C}\right)$ rooms. Throughout the experiments, the mice had free access to standard laboratory chow and were provided with tap water ad libitum. The mice were treated humanely according to international guidelines and the experiment was adhered to the Guide for the Care and Use of Laboratory Animals and approved by the Animal Ethics Committee of Qingdao Municipal Hospital, Qingdao, China.

Twelve specific pathogen-free $\mathrm{C} 57 \mathrm{BL} / 6$ mice were used and divided randomly into control $(n=6)$ and asthma $(n=6)$ groups. During the induction of asthma, the mice were sensitized by intraperitoneal injection of $50 \mu \mathrm{g}$ ovalbumin grade V (OVA) (Sigma, Germany) adsorbed on $\mathrm{Al}(\mathrm{OH}) 3$ (Alumlnject $\mathrm{C}$, Perbio, Belgium) on days 1 and 7. Animals were fed $50 \mu \mathrm{g}$ of OVA via nasal drops on days $14-17$, as previously described. ${ }^{23}$ Each control mouse was administered $0.9 \% \mathrm{NaCl}$ as placebo.

\section{Histological Analysis}

On day 17 , the mice were anesthetized by intraperitoneal injection of $10 \%$ pentobarbital. After anesthesia induction, a catheter was intubated through the trachea. The left lung was removed after ligation of the left main bronchus, and the lung tissues were then quickly fixed in $10 \%$ neutral-buffered formalin. The formalin-fixed tissues were embedded in paraffin sectioned $(4 \mathrm{~mm})$ and stained with hematoxylin and eosin (H\&E) to identify histopathological lesions. 


\section{ELISA and Flow Cytometry}

The blood samples were collected by cardiac puncture, and centrifuged at $3000 \mathrm{rpm}$ for $5 \mathrm{~min}$ at $4{ }^{\circ} \mathrm{C}$. IgE level was measured by an ELISA kit (BD Bioscience) according to the manufacturer's instructions.

After the left lung was removed, $1 \mathrm{~mL}$ of iced PBS was slowly injected into the trachea with a syringe. The bronchoalveolar lavage fluid (BALF) was washed several times, counted on a blood cell counting plate, and $5 \times 10^{5}$ cells were added to the 7AAD-percP (BD Biosciences), CD45-eflour 450 (Biolegend), CD11b-ITC (Biolegend), and SiglecF-PE (Biolegend), according to the specification. Antibody surface staining of BALF cells. After $30 \mathrm{~min}$ of light staining on ice, $200 \mu \mathrm{L}$ PBS was added, the solution was centrifugated at $5000 \mathrm{r} / \mathrm{min}$ for $5 \mathrm{~min}$, and excess antibody was washed off. The cells were resuspended in $300 \mu \mathrm{L}$ of PBS or a 1:1 mixture of PBS and 4\% paraformaldehyde and then transferred to a flow tube for on-machine detection using flow cytometry (ACEA Novo Cyte ${ }^{\mathrm{TM}}$ ).

\section{Urine Collection and Sample Preparation}

Urine samples were collected from six asthmatic mice at days 2, 8, 15, and 18 and six control mice. The mice were individually housed in the metabolic cages for 4 hours. During urine collection, no food was provided to the mice to avoid urine contamination. After collection, the urine samples were centrifuged at $2000 \mathrm{~g}$ for $30 \mathrm{~min}$ at $4^{\circ} \mathrm{C}$ immediately and then stored at $-80^{\circ} \mathrm{C}$.

For tryptic digestion, the proteins were digested with trypsin (Promega, USA) using filter-aided sample preparation methods. ${ }^{24}$ Briefly, $100 \mu \mathrm{g}$ of the protein sample was loaded on the $10-\mathrm{kD}$ filter unit (Pall, USA). The protein solution was reduced with $4.5 \mathrm{mM}$ DTT for $1 \mathrm{~h}$ at $37^{\circ} \mathrm{C}$ and then alkylated with $10 \mathrm{mM}$ of indoleacetic acid for 30 min at room temperature in the dark. The proteins were digested with trypsin (enzyme-to-protein ratio of 1:50) for $14 \mathrm{~h}$ at $37^{\circ} \mathrm{C}$. The peptides were desalted on Oasis HLB cartridges (Waters, USA) and lyophilized for trap column fractionation and LC-DIA-MS/MS analysis.

\section{Spin Column Separation}

The pooled peptides sample were fractionated using a high-pH reversed-phase peptide fractionation kit (Thermo Pierce, USA) according to the manufacturer's instructions. Briefly, $60 \mu \mathrm{g}$ of the pooled peptide sample was loaded onto the spin column. Ten different fractions were collected by centrifugation, including flow-through fraction, wash fraction, and eight step gradient sample fractions $(5,7.5,10,12.5,15,17.5,20$, and $50 \%$ acetonitrile). The fractionated samples were lyophilized and used for the LC-DDA-MS/MS analysis.

\section{Liquid Chromatography-Tandem Mass Spectrometry (LC-MS/MS) Analysis}

The Orbitrap Fusion Lumos Tribrid Mass Spectrometer coupled with an EASY-nLC 1200 HPLC system (Thermo Scientific, Germany) was used for the DDA-MS and DIAMS analysis. The digested peptides were dissolved in $0.1 \%$ formic acid and loaded on a trap column $(75 \mu \mathrm{m} \times 2 \mathrm{~cm}, 3$ $\left.\mu \mathrm{m}, \mathrm{C} 18,100 \mathrm{~A}^{\circ}\right)$. The eluent was transferred to a reversedphase analytical column $(50 \mu \mathrm{m} \times 250 \mathrm{~mm}, 2 \mu \mathrm{m}, \mathrm{C} 18,100$ $\mathrm{A}^{\circ}$ ). The eluted gradient was $5-30 \%$ buffer B for $90 \mathrm{~min}$. The calibration kit (iRT kit from Biognosys, Switzerland) was spiked at a concentration of $1: 20 \mathrm{v} / \mathrm{v}$ in all samples. DDA-MS: full scan, $350-1550 \mathrm{~m} / \mathrm{z}$ at 60,000 ; cycle time: 3 secs (top speed mode); AGC 2e5; MS/MS scans in the Orbitrap at a resolution of 15,000; isolation window $2 \mathrm{Da}$, HCD 32\%, AGC 5e5, 50 ms. DIA-MS: 32 windows.

\section{DIA Quantification Analysis}

The raw data files were processed using Proteome Discoverer (version 2.1; Thermo Scientific, Germany) with SEQUEST HT against the SwissProt ratus database (released in May 2019, containing 8086 sequences). The search parameters consisted of the parent ion mass tolerance, $10 \mathrm{ppm}$; fragment ion mass tolerance, $0.02 \mathrm{Da}$; fixed modifications, carbamidomethylated cysteine $(+58.00 \mathrm{Da})$; and variable modifications, oxidized methionine $(+15.995 \mathrm{Da})$ and deamidated glutamine and asparagine (+0.984 Da). Other settings included the default parameters. ${ }^{25}$ The DIAMS raw files were imported to Spectronaut Pulsar with the default settings. In brief, all results were filtered by an FDR of $1 \%$. Peptide intensity was calculated by summing the peak areas of their respective fragment ions for MS2.

\section{Bioinformatics Analysis}

Bioinformatics analysis was conducted in order to better study the biological function of the dysregulated proteins. Gene Ontology (GO) analysis was performed on the urinary differentially altered proteins identified at the discovery phase (http://www.geneontology.org/). ${ }^{26,27}$ Protein-protein interaction (PPI) networks were constructed using the STRING database (http://www.string-db.org), which is a database of 

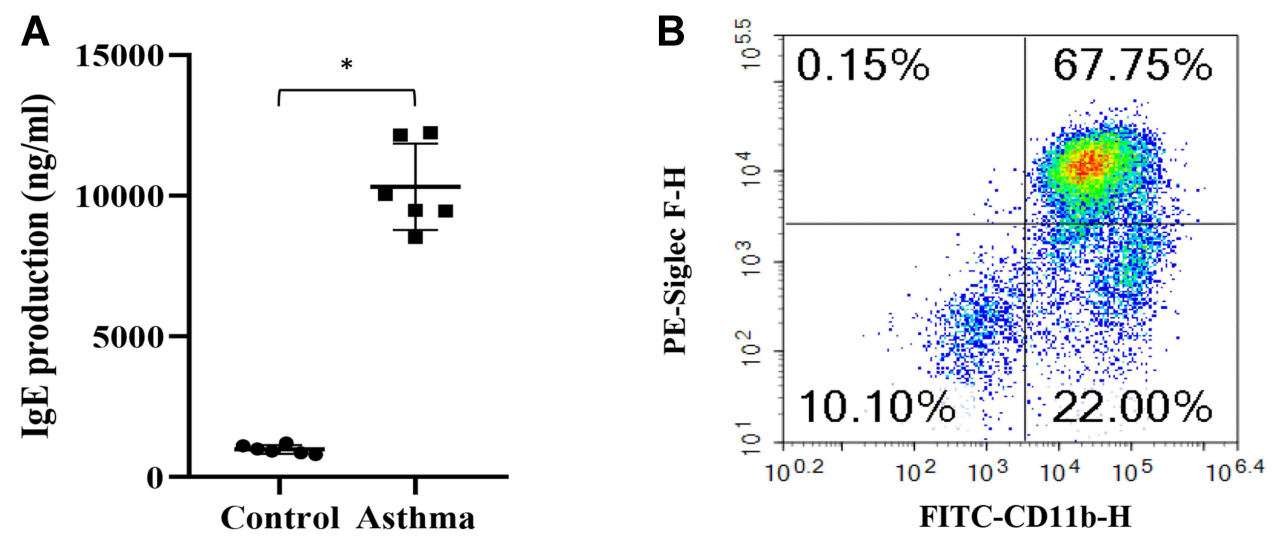

Figure I The ELISA and flow cytometric analysis results. (A) Blood samples were collected and level of serum IgE was measured ( $\mathrm{n}=6$ ). (B) The ration of eosinophils in bronchoalveolar lavage fluid (BALF) in asthmatic mice. ${ }^{*} p<0.001$ compared to control group.

known and predicted protein interactions, including direct (physical) and indirect (functional) associations.

The "Wu Kong" platform (https://www.omicsolution. org/wkomics/main/) was used for statistical analysis. The differential proteins were selected using one-way ANOVA, and p-values were adjusted using the Benjamini-Hochberg method. Significance was set at a p-value of $<0.05$ and a fold change of 1.5 .

\section{Results}

\section{Characterization of OVA-Induced}

\section{Asthmatic Mice}

To investigate the dynamic urinary proteome changes in asthma progression, we established an OVA-induced asthma model. After challenging with OVA, the serum IgE levels were measured (Figure 1A). The results showed that the $\mathrm{IgE}$ levels in the OVA-treated group were increased. Next, flow cytometry was performed on eosinophils in BALF. After removing the dead cells $\left(7 \mathrm{AAD}^{+}\right.$, the proportion of eosinophils in the leukocytes $\left(\mathrm{CD} 45^{+}\right)$was analyzed (Figure 1B). The ratio of eosinophils $\left(\mathrm{CD}_{11 b^{+}}\right.$siglecF $\left.^{+}\right)$in BLAF was $67.75 \%$ after 17 days of OVA induction.

The hematoxylin-eosin (HE) stained microscopic features of the lung from control mice showed a normal structure: the alveolar wall structure is intact, there is no thickening, and there is no exudate in the alveolar cavity (Figure 2A), and alveolar epithelial cells are arranged in order (Figure 2B). Compared to the control group, HEstained of the lung in asthma group showed alveolar destruction and alveolar wall thickening (Figure 2C), as well as pulmonary fibrosis and neutrophil infiltration (Figure 2D). These pathological changes reveal the success of OVA-induced asthma modeling.

\section{Dynamic Urinary Proteome Changes in OVA-Induced Asthmatic Mice}

For a preliminary investigation of changes in the urinary proteome with asthma progression, three urine samples from the control group and 12 samples taken at four time points (days 2, 8, 15, and 18) from the asthma group were analyzed by LC-DIA-MS/MS workflow.

Overall, a total of 331 urinary protein groups were identified; all details are listed in Supporting Table S1. Among these, 53 proteins were significantly changed in asthmatic mice compared to control mice (1.5-fold change, adjust $\mathrm{P}<0.05$; Table 1 ).

At day 2, 26 differential proteins, 21 of which increased and five of which decreased, were identified. At day 8, 24 differential proteins, 15 of which increased and nine of which decreased, were identified. At day 15, 14 differential proteins, six of which increased and nine of which decreased, were identified. At day 18, 20 differential proteins, seven of which increased and 13 of which decreased, were identified (Figure 3).

\section{Gene Ontology Analysis of Differential Proteins}

The GO functional annotation was performed on the differentially expressed proteins in asthmatic mice. A total of 53 dysregulated proteins, at four time points, were annotated and classified to be involved with certain biological processes (Figure 4).

The GO enrichment analysis showed that inflammation or immune responses, such as acute-phase response, innate immune response, B cell receptor signaling pathway, complement activation, positive regulation of $\mathrm{B}$ cell activation, and phagocytosis, were the mainly involved biological 

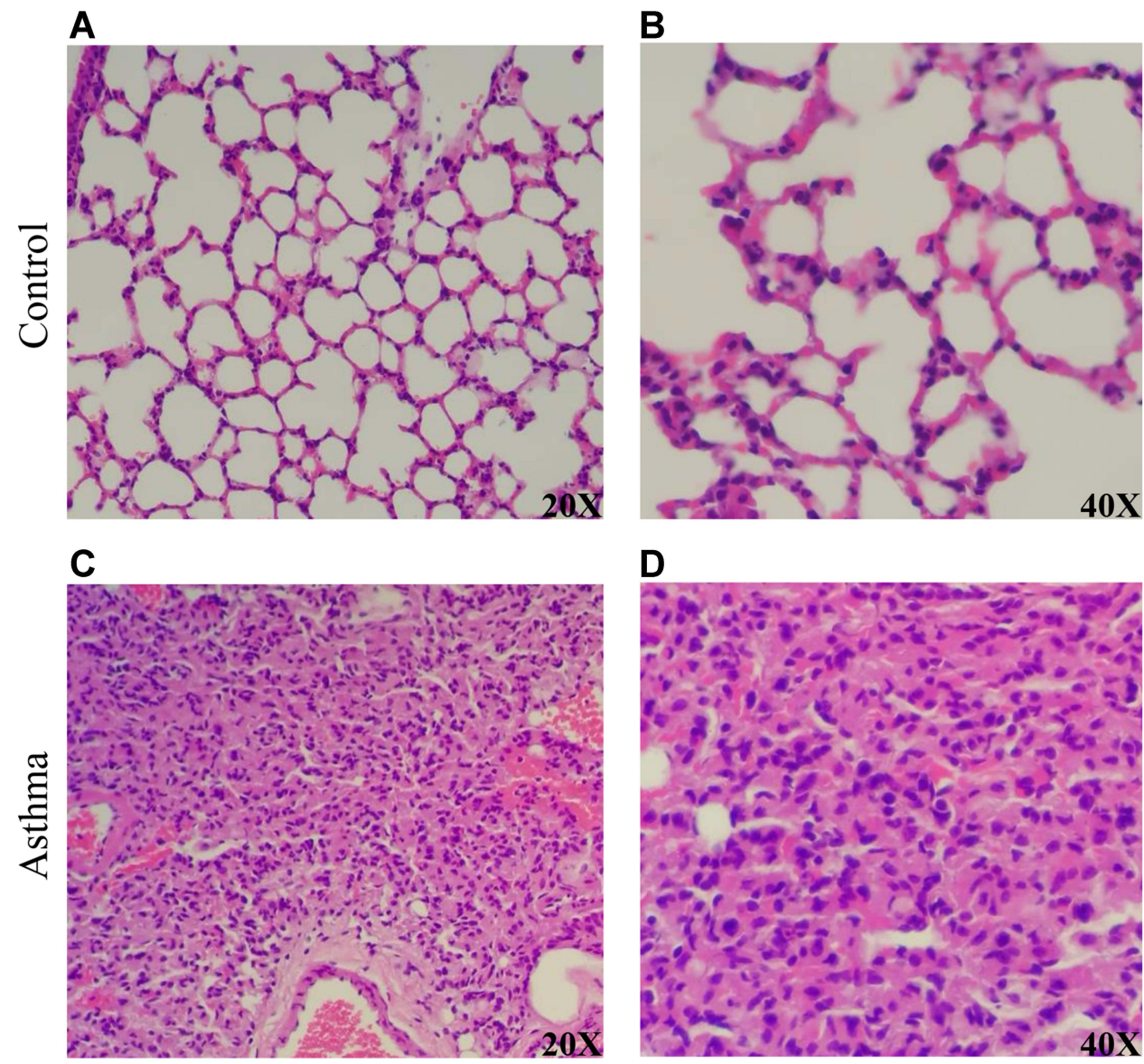

Figure 2 Pathological results of hematoxylin and eosin (HE) staining in the lungs of asthma and control mice. (A) The lung of normal control mice (20x). (B) The lung of normal control mice (40x). (C) The lung of asthmatic mice (20x). (D) The lung of asthmatic mice (20x).

processes at the four time points. Coagulation factor II, haptoglobin, and alpha-1-acid glycoprotein 1 were enriched in acute-phase response. Beta- 2 microglobulin, cathelicidin antimicrobial peptide, complement factor B, immunoglobulin heavy chain, immunoglobulin heavy constant gamma 2A, immunoglobulin kappa constant, and lipocalin 2 were enriched in innate immune response. These results indicate that urine can reflect biological responses in the body during the progression of asthma.

In the cellular component category, most of these differential proteins were extracellular region, extracellular space, blood microparticle, extracellular exosome, and immunoglobulin complex proteins (Figure 4B). In the molecular function category, serine-type endopeptidase activity, immunoglobulin receptor binding, hormone activity, and serine-type peptidase activity were overrepresented on days 2 and 8 . Immunoglobulin receptor binding, insulin-activated receptor activity, small molecule binding, and transporter activity were overrepresented on days 15 and 18 (Figure 4C).

\section{Protein-Protein Interaction Network of the Differential Proteins}

To better understand the pathogenic mechanisms of OVAinduced asthma, the PPI network for 53 differential proteins was constructed using STRING (Figure 5). The STRING PPI network analysis revealed that the average node degree is 3.84, average local clustering coefficient is 0.443 , and PPI enrichment p-value is $<1.0 \mathrm{e}-16$. This indicates that these proteins have more interactions among themselves than what would be expected for a random set of proteins of similar size drawn from the genome.

\section{Differential Urinary Proteins Related to Asthma}

Among these 53 differential proteins, 18 that had human orthologs were reported to be closely associated with asthma (Table 2). The first 13 differential proteins shown in the table were changed on days 2 and 8, which was the early stage at which a low dose of OVA was intraperitoneally injected for 
Table I Details of the Differential Urinary Proteins in OVA-Induced Asthmatic Mice

\begin{tabular}{|c|c|c|c|c|c|}
\hline \multirow[t]{2}{*}{ UniProt ID } & \multirow[t]{2}{*}{ Protein Name } & \multicolumn{4}{|c|}{ Fold Change } \\
\hline & & D2 & D8 & DI5 & DI8 \\
\hline PI922I & Prothrombin & 2.15 & 3.02 & 2.02 & 2.19 \\
\hline PI550I & Prostatic spermine-binding protein & 15.94 & & 7.56 & 0.15 \\
\hline Q61646 & Haptoglobin & 7.12 & 3.24 & & 1.71 \\
\hline Q9D3H2 & Odorant-binding protein la & 4.23 & 10.98 & & 1.86 \\
\hline Q8C6C9 & Protein LEGI homolog & 2.78 & & 1.51 & 1.89 \\
\hline P01878 & Ig alpha chain $C$ region & & 2.68 & 2.01 & 2.13 \\
\hline P01864 & Ig gamma-2A chain $C$ region secreted form & 0.29 & 0.27 & 0.33 & \\
\hline Q02596 & Glycosylation-dependent cell adhesion molecule I & & 0.36 & 0.60 & 0.61 \\
\hline Q9102 & Secretoglobin family $2 B$ member 20 & 81.62 & 21.94 & & \\
\hline P5।437 & Cathelicidin antimicrobial peptide & 7.93 & 17.65 & & \\
\hline Q60590 & Alpha-I-acid glycoprotein I & 4.49 & 1.61 & & \\
\hline P04I86 & Complement factor B & 2.56 & 2.92 & & \\
\hline P97426 & Eosinophil cationic protein I & 1.88 & 1.59 & & \\
\hline Q9EP95 & Resistin-like alpha & 0.19 & 0.10 & & \\
\hline PII588 & Major urinary protein I & 4.12 & & & 0.39 \\
\hline P21614 & Vitamin D-binding protein & 0.55 & & 0.38 & \\
\hline P01633 & Ig kappa chain VI9-17 & 0.42 & & & \\
\hline Q9ET22 & Dipeptidyl peptidase 2 & & 0.56 & 0.49 & \\
\hline Q9JHY4 & WAP four-disulfide core domain protein I5B & & 0.61 & & 0.40 \\
\hline P01837 & Ig kappa chain $C$ region & & 0.59 & & 0.40 \\
\hline P00688 & Pancreatic alpha-amylase & & & 0.62 & 0.59 \\
\hline Q92III & Serotransferrin & & & 0.59 & 0.36 \\
\hline Q91X72 & Hemopexin & & & 0.56 & 0.44 \\
\hline P42567 & Epidermal growth factor receptor substrate 15 & 22.40 & & & \\
\hline P02816 & Prolactin-inducible protein homolog & 4.29 & & & \\
\hline Q8KIH9 & Odorant-binding protein $2 \mathrm{a}$ & 3.58 & & & \\
\hline Q99P86 & Resistin-like beta & 2.38 & & & \\
\hline P01887 & Beta-2-microglobulin & 2.28 & & & \\
\hline Q07456 & Protein AMBP & 1.83 & & & \\
\hline P07759 & Serine protease inhibitor $\mathrm{A} 3 \mathrm{~K}$ & 1.69 & & & \\
\hline P20918 & Plasminogen & 1.61 & & & \\
\hline Q61398 & Procollagen C-endopeptidase enhancer I & 1.60 & & & \\
\hline G5E86I & Sodium channel and clathrin linker I & 1.58 & & & \\
\hline Q80TI9 & Hepcidin-2 & 0.19 & & & \\
\hline Q60997 & Deleted in malignant brain tumors I protein & & 5.20 & & \\
\hline P62806 & Histone $\mathrm{H} 4$ & & 25.93 & & \\
\hline PII672 & Neutrophil gelatinase-associated lipocalin & & 5.87 & & \\
\hline P607I0 & Actin, cytoplasmic I & & 3.21 & & \\
\hline Q9IVW3 & SH3 domain-binding glutamic acid-rich-like protein 3 & & 2.25 & & \\
\hline Q8K426 & Resistin-like gamma & & 1.74 & & \\
\hline Q9Z0M9 & Interleukin-I8-binding protein & & 0.55 & & \\
\hline P23780 & Beta-galactosidase & & 0.54 & & \\
\hline POCW02 & Lymphocyte antigen $6 \mathrm{Cl}$ & & 0.51 & & \\
\hline P70269 & Cathepsin E & & & 1.97 & \\
\hline 008997 & Copper transport protein ATOXI & & & 1.72 & \\
\hline O70570 & Polymeric immunoglobulin receptor & & & 0.60 & \\
\hline Q6SJQ5 & CMRF35-like molecule 3 & & & & 4.26 \\
\hline Q9JLB4 & Cubilin & & & & 1.62 \\
\hline A2BIM 8 & Major urinary protein 18 & & & & 0.67 \\
\hline
\end{tabular}

(Continued) 
Table I (Continued).

\begin{tabular}{|c|c|c|c|c|c|}
\hline \multirow[t]{2}{*}{ UniProt ID } & \multirow[t]{2}{*}{ Protein Name } & \multicolumn{4}{|c|}{ Fold Change } \\
\hline & & D2 & D8 & DI5 & DI8 \\
\hline P07724 & Serum albumin & & & & 0.66 \\
\hline P04939 & Major urinary protein 3 & & & & 0.63 \\
\hline Q00897 & Alpha-I-antitrypsin I-4 & & & & 0.50 \\
\hline Q60932 & Voltage-dependent anion-selective channel protein I & & & & 0.47 \\
\hline
\end{tabular}

sensitization of mice, and the last seven differential proteins were changed on days 15 and 18, during which a high dose of OVA was administered via nasal inhalation to provoke asthma.

\section{Discussion}

In this study, urine samples were collected from six control mice and six asthmatic mice on days 2, 8, 15, and 18 for proteome analysis to identify potential biomarkers for asthma. Compared to control mice, 53 proteins were found to have undergone significant changes in the urine samples of asthmatic mice.

On days 2 and 8, 13 differential proteins that had human orthologs were reported to be closely associated with asthma. Among these, six urinary proteins were changed on days 2 and 7, and the trend was consistent at each time point; these proteins hold the potential to be biomarkers for the early screening of asthma attack. For example, cathelicidin antimicrobial peptide (CRAMP) significantly enhanced the infiltration of inflammatory cells and accumulation of pro-inflammatory Th2 cytokine IL-13 and IL-33 in BALF and exacerbated lung tissue inflammation and airway goblet cell hyperplasia in a previous study. ${ }^{28}$ CRAMP plays an important role in the accumulation of inflammatory monocyte-derived dendritic cells in the peribronchiolar tissue in allergic airway inflammation. ${ }^{29}$ Serum eosinophil cationic protein 1 (ECP) was positively correlated with the severity of an

\section{Day 8 Day 15}

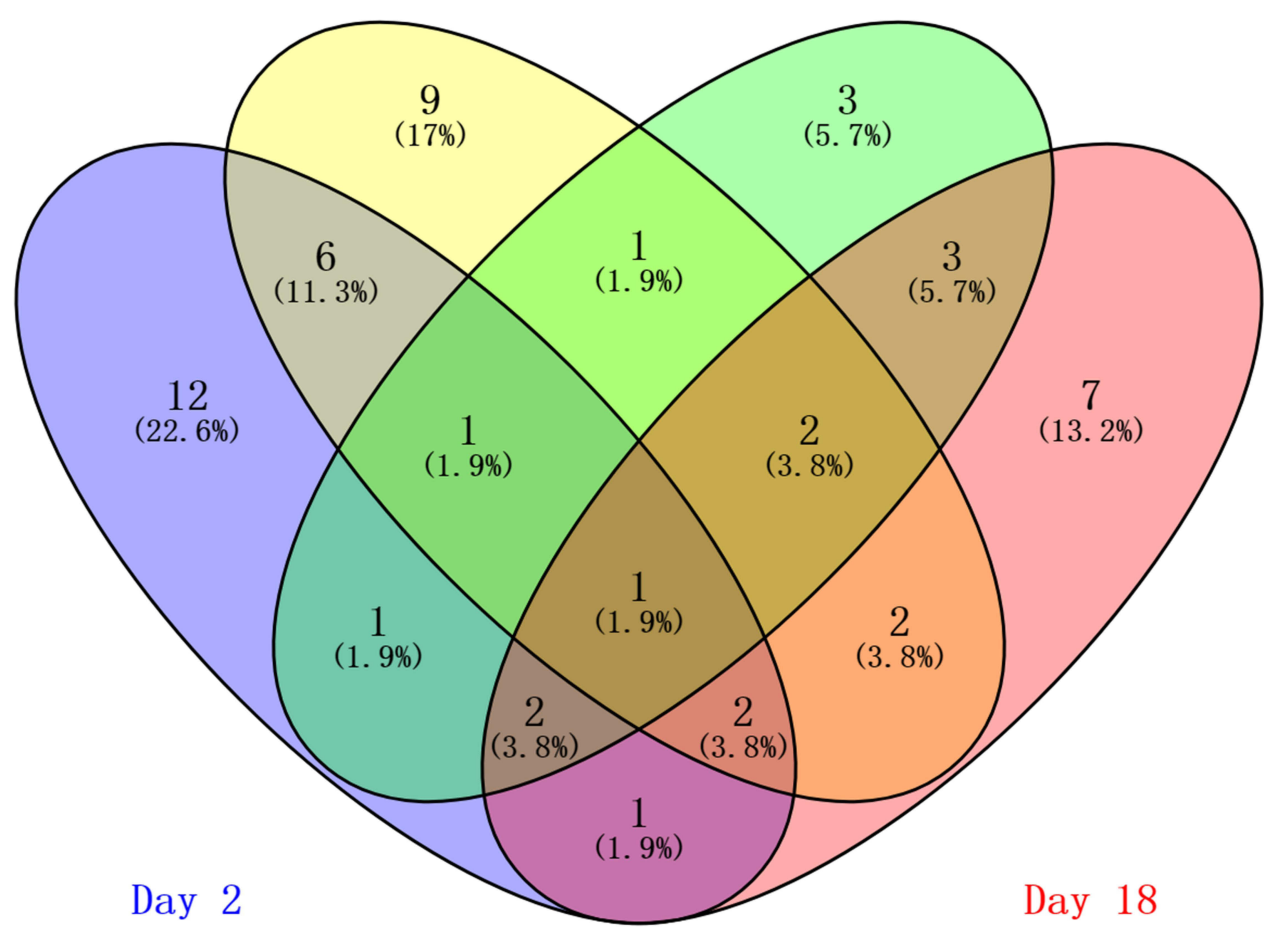

Figure 3 Vein diagram of the differential urinary proteins in asthmatic mice compared with control mice. 
A complement activation, classical pathway B cell receptor signaling pathway cellular iron ion homeostasis positive regulation of lipid metabolic process energy reserve metabolic process locomotor rhythm mitochondrion morphogenesis

B

C

serine-type endopeptidase activity immunoglobulin receptor binding insulin-activated receptor activity hormone activity serine-type peptidase activity small molecule binding transporter activity

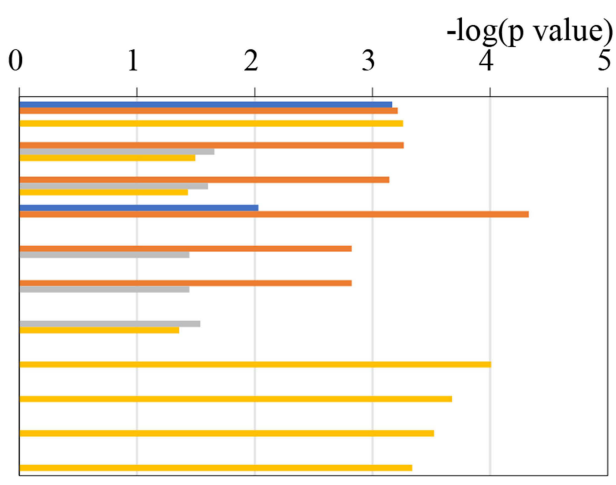

- Day 2 Day 8 - Day 15 Day 18

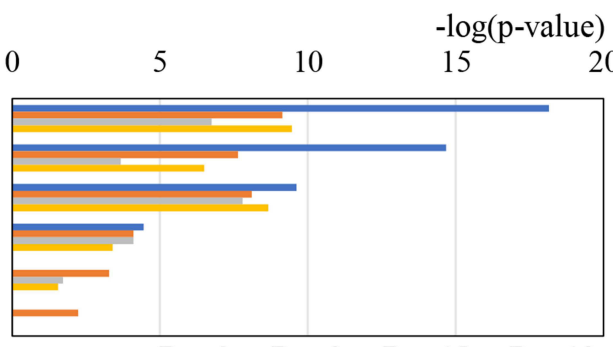

घay 2 Day 8 Day 15 Day 18

0 $24^{-\log (\mathrm{p} \text {-value })} 6$

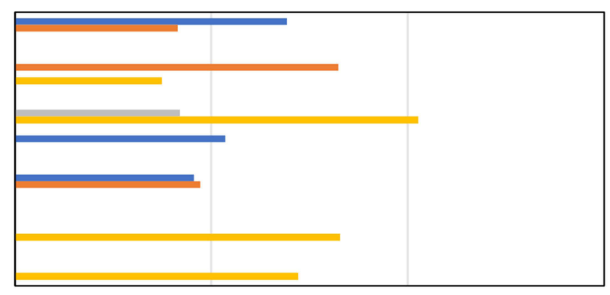

घay $2 \backsim$ Day $8 \quad$ Day $15 \backsim$ Day 18

Figure $4 \mathrm{GO}$ analysis of the differential proteins at days 2, 8, 15 and 18 in OVA-induced mice. (A) Biological process; (B) Cellular component; (C) Molecular function.

asthma attack. ${ }^{30,31}$ Elevated serum ECP level had the highest likelihood of fixed airflow obstruction among patients with asthma. ${ }^{32}$ Serum ECP level is helpful in assessing the efficacy of inhaled corticosteroids therapy in bronchial asthma. ${ }^{33}$ Increased serum haptoglobin (HP) level is seen in patients with asthma, asthma exacerbation and 24 hours after allergen challenge in late responders. ${ }^{34}$ As part of its tissue repair function, HP can induce differentiation of fibroblast progenitor cells into lung fibroblasts in airway remodeling in patients with asthma. ${ }^{35}$ Patients with asthma had 61\% higher maximal prothrombin (PT) conversion rate than controls. ${ }^{36}$ Plasma PT level was significantly higher in patients with nonallergic asthma than in controls. $^{37}$ Alpha-1-acid glycoprotein 1 was altered in patients with atopic asthma, and the presence of asthma symptoms correlated with increased glycan branching of AGP in both plasma and BALF. ${ }^{38}$ Rhinovirus infection is the most common trigger of the acute exacerbations of asthma; the infection stimulated stimulates the expression of not only complement factor B but also the novel proinflammatory cytokine IL-32. ${ }^{39}$

On days 15 and 18, the acute attack stage on which a high-dose of OVA was nasal inhalation to provoke asthma, seven differential proteins that had human orthologs were reported to be closely associated with asthma. Besides HP and vitamin D-binding protein (VDBP), which were altered on day 2, another five differential proteins also showed changes; these proteins hold the potential to be biomarkers for the diagnosis of asthma attack. For example, serum VDBP was significantly upregulated in the steroid-resistant asthma group compared with the steroid-sensitive asthma group in a previous study. ${ }^{40}$ Another study reported upregulated VDBP expression both in serum and BALF of isocyanate-occupational asthma 


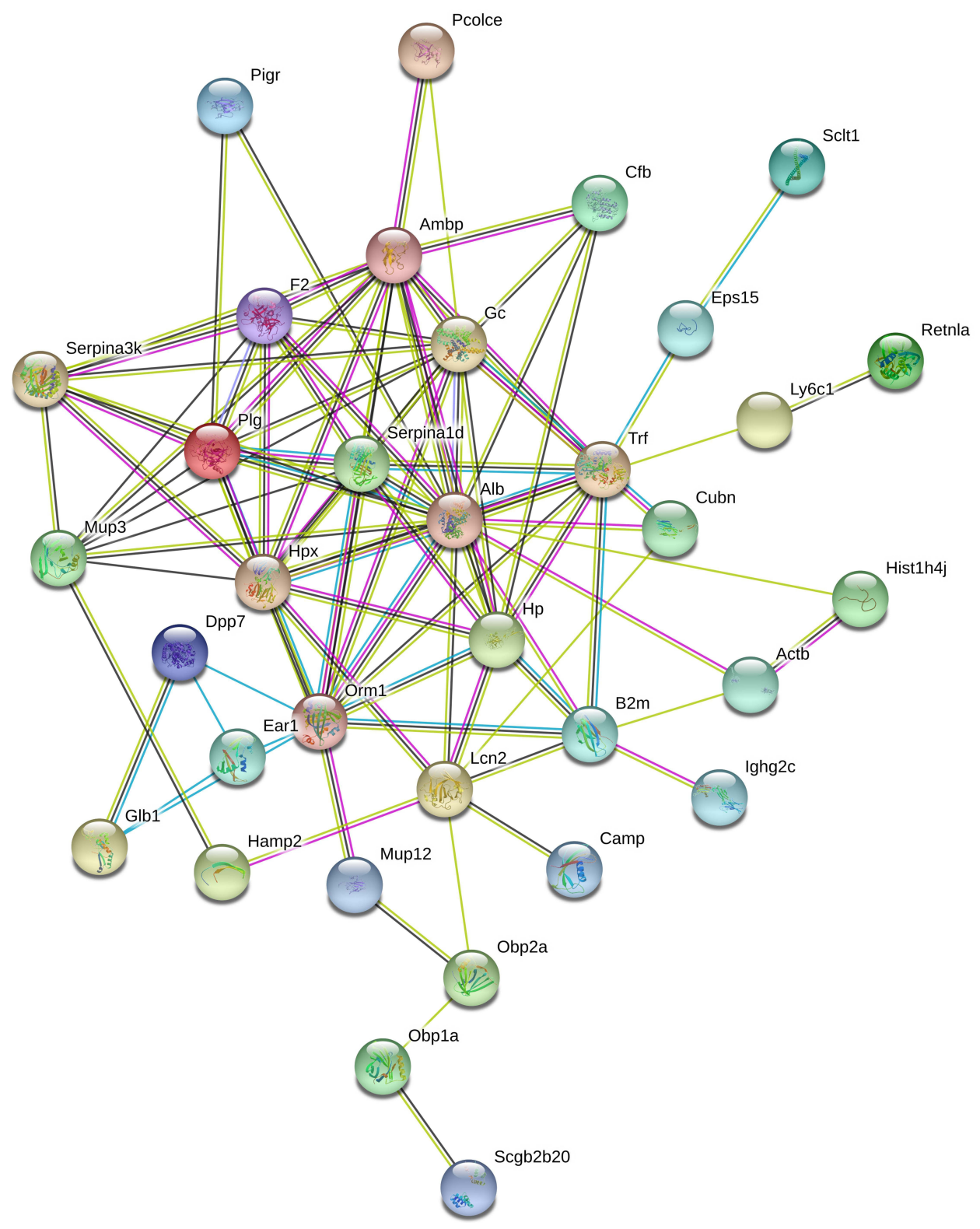

Figure 5 STRING PPI network analysis of the 53 differential proteins in OVA-induced asthma mouse model. The average node degree is 3.84 , average local clustering coefficient is 0.443 , and PPI enrichment $\mathrm{p}$-value is $<1.0 \mathrm{e}-16$.

(OA) patients compared with controls. ${ }^{41,42}$ These findings were consistent with those of studies in which VDBP was identified in the BALF of patients with asthma using proteomic analysis. $^{43,44}$ In vivo, Cathepsin E deficiency resulted in reduced lymphocyte influx after allergen sensitization and challenge in both investigated airway inflammation models. ${ }^{45}$ Polymeric immunoglobulin receptor protein level was decreased in the bronchial epithelium from patients with asthma, ${ }^{46}$ whereas PIGR demonstrated significantly enhanced upregulation in the BALF of OVAsensitized mice. ${ }^{47}$ The prevalence of alpha-1-antitrypsin 1-4 deficiency was low in patients with severe persistent asthma. ${ }^{48}$ Serotransferrin was upregulated in patients with methylene diphenyl diisocyanate (MDI)-induced occupational asthma and was used as serologic markers of MDIOA. ${ }^{49}$ Hemopexin was upregulated in the local lymph nodes and serum of toluene-2,4-diisocyanate-induced asthmatic mice. ${ }^{50}$ Individuals with asthma-COPD overlap exhibited significantly elevated serum levels of HPX compared with healthy control subjects. ${ }^{51}$

Urine can be collected noninvasively and continuously, which is a good resource of biomarker for asthma. Despite the advantage of urine as a promising biomarker source, urine proteins are affected by many factors. Therefore, to 
Table 2 Differential Urinary Proteins Related to Asthma

\begin{tabular}{|c|c|c|c|c|}
\hline UniProt ID & Protein Name & Human Homolog & Trend & Asthma \\
\hline P5।437 & Cathelicidin antimicrobial peptide & P49913 & $\uparrow$ & OVA-induced airway inflammation \\
\hline P97426 & Eosinophil cationic protein I & PI2724 & $\uparrow$ & Bronchial asthma \\
\hline PI922I & Prothrombin & P00734 & $\uparrow$ & Asthma \\
\hline Q60590 & Alpha-I-acid glycoprotein I & $\mathrm{P} 02763$ & $\uparrow$ & Asthma \\
\hline P04I86 & Complement factor B & P0075I & $\uparrow$ & Rhinovirus \\
\hline Q99P86 & Resistin-like protein beta & Q9BQ08 & $\uparrow$ & Asthma, allergic asthma \\
\hline POI 887 & Beta-2-microglobulin & P6I769 & $\uparrow$ & Asthma \\
\hline P62806 & Histone $\mathrm{H} 4$ & P62805 & $\uparrow$ & OVA-induced airway inflammation \\
\hline PII 672 & Neutrophil gelatinase-associated lipocalin & P80I88 & $\uparrow$ & Asthma \\
\hline Q9Z0M9 & Interleukin-18-binding protein & O95998 & $\downarrow$ & Asthma \\
\hline P23780 & Beta-galactosidase & PI6278 & $\downarrow$ & Neonatal and pediatric asthma \\
\hline Q61646 & Haptoglobin & P00738 & $\uparrow$ & Asthma \\
\hline $\mathrm{P} 21614$ & Vitamin D-binding protein & P02774 & $\downarrow$ & Asthma, isocyanate-occupational asthma \\
\hline P70269 & Cathepsin E & PI409I & $\uparrow$ & Allergic asthma \\
\hline O70570 & Polymeric immunoglobulin receptor & P01833 & $\downarrow$ & Asthma, OVA-induced airway inflammation \\
\hline Q00897 & Alpha-I-antitrypsin I-4 & P01009 & $\downarrow$ & Severe asthma \\
\hline Q92III & Serotransferrin & P02787 & $\downarrow$ & Occupational asthma \\
\hline Q91X72 & Hemopexin & P02790 & $\downarrow$ & TDI-induced asthma, asthma and COPD \\
\hline
\end{tabular}

sort out factors associated with any particular pathophysiological condition, especially in human samples, is challenging. To circumvent this problem, simpler systems, such as animal models, should be used to establish the direct relation between disease progression and urine changes. To avoid contamination, the mice were individually housed in the metabolic cages, and no food was provided during urine collection. To avoid protein degradation, the urine samples were centrifuged immediately after 4 hours collection, and the stored at $-80^{\circ} \mathrm{C}$.

Overall, this study was a preliminary study with a small number of OVA-induced asthmatic mice. In future studies, the urinary protein biomarkers should be further evaluated in urine samples of patients with asthma to test their sensitivity and specificity. The findings of these studies will have potential applications in monitoring in treatment and prevention studies.

\section{Conclusions}

Our results suggest that the urinary proteome could reflect dynamic pathophysiological changes in asthma; therefore, these differential proteins could be potential biomarkers for the early diagnosis of asthma.

\section{Acknowledgments}

The National Key Research and Development Program of China (2018YFC0910202, 2016YFC1306300); National Natural Science Foundation of China (82000881);
Beijing Natural Science Foundation (7172076); Beijing Cooperative Construction Project (110651103); Beijing Normal University (11100704).

\section{Disclosure}

The authors declare that they have no competing interests.

\section{References}

1. Bousquet J, Humbert M. GINA 2015: the latest iteration of a magnificent journey. Eur Respir J. 2015;46(3):579-582. doi:10.1183/13993003.01084-2015

2. To T, Stanojevic S, Moores G, et al. Global asthma prevalence in adults: findings from the cross-sectional world health survey. $B M C$ Public Health. 2012;12(1):204. doi:10.1186/1471-2458-12-204

3. Lai CK, Beasley R, Crane J, et al. Global variation in the prevalence and severity of asthma symptoms: phase three of the International Study of Asthma and Allergies in Childhood (ISAAC). Thorax. 2009;64(6):476-483. doi:10.1136/thx.2008.106609

4. Abramson MJ, Perret JL, Dharmage SC, McDonald VM, McDonald CF. Distinguishing adult-onset asthma from COPD: a review and a new approach. Int $J$ Chron Obstruct Pulmon Dis. 2014;9:945-962. doi:10.2147/COPD.S46761

5. Moore WC, Meyers DA, Wenzel SE, et al. Identification of asthma phenotypes using cluster analysis in the severe asthma research program. Am J Respir Crit Care Med. 2010;181(4):315-323. doi:10.1164/rccm.200906-0896OC

6. Wenzel SE. Asthma phenotypes: the evolution from clinical to molecular approaches. Nat Med. 2012;18(5):716-725. doi:10.1038/nm.2678

7. Levy ML, Quanjer PH, Booker R, et al.; A General Practice Airways Group (GPIAG)1 document, in association with the Association for Respiratory Technology \& Physiology (ARTP)2 and Education for Health. Diagnostic spirometry in primary care: proposed standards for general practice compliant with American Thoracic Society and European Respiratory Society recommendations. Prim Care Respir J. 2009;18(3):130-147. 
8. Miller MR, Hankinson J, Brusasco V, et al. Standardisation of spirometry. Eur Respir J. 2005;26(2):319-338. doi:10.1183/09031 936.05.00034805

9. Inoue H, Nagase T, Morita S, Yoshida A, Jinnai T, Ichinose M. Prevalence and characteristics of asthma-COPD overlap syndrome identified by a stepwise approach. Int J Chron Obstruct Pulmon Dis. 2017;12:1803-1810. doi:10.2147/COPD.S133859

10. Silva GE, Sherrill DL, Guerra S, Barbee RA. Asthma as a risk factor for COPD in a longitudinal study. Chest. 2004;126(1):59-65. doi:10.1378/chest.126.1.59

11. Zeki AA, Schivo M, Chan A, Albertson TE, Louie S. The asthma-COPD overlap syndrome: a common clinical problem in the elderly. J Allergy. 2011;2011:861926.

12. Serban KA, Pratte KA, Bowler RP. Protein biomarkers for COPD outcomes. Chest. 2021;159(6):2244-2253. doi:10.1016/j.chest.202 1.01 .004

13. Crameri R. The potential of proteomics and peptidomics for allergy and asthma research. Allergy. 2005;60(10):1227-1237. doi:10.1111/ j.1398-9995.2005.00873.x

14. Bhowmik M, Majumdar S, Dasgupta A, Gupta Bhattacharya S, Saha S. Pilot-scale study of human Plasma proteomics identifies ApoE And IL33 as markers in atopic asthma. J Asthma Allergy. 2019;12:273-283. doi:10.2147/JAA.S211569

15. Li F, Xu D, Wang J, Jing J, Li Z, Jin X. Comparative proteomics analysis of patients with quick development and slow development Chronic Obstructive Pulmonary Disease (COPD). Life Sci. 2020;256:117829. doi:10.1016/j.1fs.2020.117829

16. de Torre C, Ying SX, Munson PJ, Meduri GU, Suffredini AF. Proteomic analysis of inflammatory biomarkers in bronchoalveolar lavage. Proteomics. 2006;6(13):3949-3957. doi:10.1002/pmic.20 0500693

17. Sim SY, Choi YR, Lee JH, et al. In-depth proteomic analysis of human bronchoalveolar lavage fluid toward the biomarker discovery for lung cancers. Proteomics Clin Appl. 2019;13(5):e1900028. doi:10.1002/prca.201900028

18. Norman KC, Moore BB, Arnold KB, O’Dwyer DN. Proteomics: clinical and research applications in respiratory diseases. Respirology. 2018;23(11):993-1003. doi:10.1111/resp.13383

19. Zhang C, Leng W, Sun C, et al. Urine proteome profiling predicts lung cancer from control cases and other tumors. EBioMedicine. 2018;30:120-128. doi:10.1016/j.ebiom.2018.03.009

20. Wang J, Zhu X, Xiong $X$, et al. Identification of potential urine proteins and microRNA biomarkers for the diagnosis of pulmonary tuberculosis patients. Emerg Microbes Infect. 2018;7(1):63 doi:10.1038/s41426-018-0066-5

21. Wu J, Li X, Zhao M, Huang H, Sun W, Gao Y. Early detection of urinary proteome biomarkers for effective early treatment of pulmonary fibrosis in a rat model. Proteomics Clin Appl. 2017;11(11-12). doi:10.1002/prca.201700103

22. Wei J, Ni N, Meng W, Gao Y. Early urine proteome changes in the Walker-256 tail-vein injection rat model. Sci Rep. 2019;9(1):13804. doi:10.1038/s41598-019-50301-1

23. Kumar RK, Herbert C, Foster PS. The "classical" ovalbumin challenge model of asthma in mice. Curr Drug Targets. 2008;9 (6):485-494. doi:10.2174/138945008784533561

24. Wisniewski JR, Zougman A, Nagaraj N, Mann M. Universal sample preparation method for proteome analysis. Nat Methods. 2009;6 (5):359-362. doi:10.1038/nmeth. 1322

25. He B, Shi J, Wang X, Jiang H, Zhu HJ. Label-free absolute protein quantification with data-independent acquisition. $J$ Proteomics. 2019;200:51-59. doi:10.1016/j.jprot.2019.03.005

26. Consortium TGO. The gene ontology resource: 20 years and still GOing strong. Nucleic Acids Res. 2019;47(D1):D330-D338.

27. Ashburner M, Ball CA, Blake JA, et al. Gene Ontology: tool for the unification of biology. Nat Genet. 2000;25(1):25-29. doi:10.1038/ 75556
28. Li Y, Chu X, Liu C, et al. Exogenous murine antimicrobial peptide CRAMP significantly exacerbates Ovalbumin-induced airway inflammation but ameliorates oxazolone-induced intestinal colitis in BALB/ c mice. Hum Vaccin Immunother. 2018;14(1):146-158. doi:10.1080/ 21645515.2017.1386823

29. Chen K, Liu M, Liu Y, et al. Signal relay by CC chemokine receptor 2 (CCR2) and formylpeptide receptor 2 (Fpr2) in the recruitment of monocyte-derived dendritic cells in allergic airway inflammation. J Biol Chem. 2013;288(23):16262-16273. doi:10.1074/jbc.M113.450635

30. Mogensen I, Alving K, Bjerg A, et al. Simultaneously elevated exhaled nitric oxide and serum-eosinophil cationic protein relate to recent asthma events in asthmatics in a cross-sectional population-based study. Clin Exp Allergy. 2016;46(12):1540-1548. doi:10.1111/cea.12792

31. Zedan M, Settin A, El-Chennawi F, El-Desouky T, Nasef N, Fouda A. Eosinophilic cationic protein: is it useful in assessing control of childhood asthma? East Mediterr Health J. 2010;16 (10):1045-1049. doi:10.26719/2010.16.10.1045

32. Mogensen I, Alving K, Dahlen SE, et al. Fixed airflow obstruction relates to eosinophil activation in asthmatics. Clin Exp Allergy. 2019;49(2):155-162. doi:10.1111/cea.13302

33. Guo CL, Sun XM, Wang XW, Guo Q. Serum eosinophil cationic protein is a useful marker for assessing the efficacy of inhaled corticosteroid therapy in children with bronchial asthma. Tohoku $J$ Exp Med. 2017;242(4):263-271. doi:10.1620/tjem.242.263

34. Lee SH, Kim KH, Kim JM, et al. Relationship between group-specific component protein and the development of asthma. Am J Respir Crit Care Med. 2011;184(5):528-536. doi:10.1164/ rccm.201006-09510C

35. Larsen K, Macleod D, Nihlberg K, et al. Specific haptoglobin expression in bronchoalveolar lavage during differentiation of circulating fibroblast progenitor cells in mild asthma. J Proteome Res. 2006;5 (6):1479-1483. doi:10.1021/pr050462h

36. Bazan-Socha S, Mastalerz L, Cybulska A, et al. Asthma is associated with enhanced thrombin formation and impaired fibrinolysis. Clin Exp Allergy. 2016;46(7):932-944. doi:10.1111/cea.12734

37. Asero R, Tedeschi A, Cugno M. Markers of autoreactivity, coagulation and angiogenesis in patients with nonallergic asthma. Allergy. 2011;66(10):1339-1344. doi:10.1111/j.1398-9995.2011.02668.x

38. Van Den Heuvel MM, Poland DC, De Graaff CS, et al. The degree of branching of the glycans of alpha(1)-acid glycoprotein in asthma. A correlation with lung function and inflammatory parameters. Am J Respir Crit Care Med. 2000;6(161):1972-1978.

39. Herbert C, Do K, Chiu V, et al. Allergic environment enhances airway epithelial pro-inflammatory responses to rhinovirus infection. Clin Sci. 2017;131(6):499-509. doi:10.1042/CS20160939

40. Jiang H, Chi X, Zhang X, Wang J. Increased serum VDBP as a risk predictor for steroid resistance in asthma patients. Respir Med. 2016;114:111-116. doi:10.1016/j.rmed.2016.03.011

41. Hur GY, Park HS. Biological and genetic markers in occupational asthma. Curr Allergy Asthma Rep. 2015;15(1):488. doi:10.1007/ s11882-014-0488-7

42. Kim SH, Choi GS, Nam YH, et al. Role of vitamin D-binding protein in isocyanate-induced occupational asthma. Exp Mol Med. 2012;44 (5):319-329. doi:10.3858/emm.2012.44.5.036

43. Wu J, Kobayashi M, Sousa EA, et al. Differential proteomic analysis of bronchoalveolar lavage fluid in asthmatics following segmental antigen challenge. Mol Cell Proteomics. 2005;4(9):1251-1264. doi:10.1074/mcp.M500041-MCP200

44. Noël-Georis I, Bernard A, Falmagne P, Wattiez R. Database of bronchoalveolar lavage fluid proteins. J Chromatogr B Analyt Technol Biomed Life Sci. 2002;771(1-2):221-236. doi:10.1016/ S1570-0232(02)00114-9

45. Pilzner C, Buhling F, Reinheckel T, et al. Allergic airway inflammation in mice deficient for the antigen-processing protease cathepsin $\mathrm{E}$. Int Arch Allergy Immunol. 2012;159(4):367-383. doi:10.1159/ 000338288 
46. Ladjemi MZ, Gras D, Dupasquier S, et al. Bronchial epithelial IgA secretion is impaired in asthma. Role of IL-4/IL-13. Am J Respir Crit Care Med. 2018;11:197.

47. Kang X, Li N, Wang M, et al. Adjuvant effects of ambient particulate matter monitored by proteomics of bronchoalveolar lavage fluid. Proteomics. 2010;10(3):520-531. doi:10.1002/pmic.200900573

48. Ousavi SA, Mohammadzadeh V, Loni E. MDetermination of alpha-1 antitrypsin level in patients with severe asthma. Tanaffos. 2013;12 (4):19-22.

49. Feldman JM, Mayefsky L, Beckmann L, Lehrer PM, Serebrisky D, Shim C. Ethnic differences in asthma-panic disorder comorbidity. $J$ Allergy Clin Immunol. 2010;125(3):760-762. doi:10.1016/j. jaci.2009.11.002
50. Haenen S, Clynen E, Vooght VD, et al. Proteome changes in auricular lymph nodes and serum after dermal sensitization to toluene diisocyanate in mice. Proteomics. 2012;12(23-24):3548-3558. doi:10.1002/pmic. 201200264

51. Verrills NM, Irwin JA, He XY, et al. Identification of novel diagnostic biomarkers for asthma and chronic obstructive pulmonary disease. Am J Respir Crit Care Med. 2011;183(12):1633-1643. doi:10.1164/ rccm.201010-1623OC

\section{Publish your work in this journal}

The Journal of Asthma and Allergy is an international, peer-reviewed open-access journal publishing original research, reports, editorials and commentaries on the following topics: Asthma; Pulmonary physiology; Asthma related clinical health; Clinical immunology and the immunological basis of disease; Pharmacological interventions and new therapies. The manuscript management system is completely online and includes a very quick and fair peer-review system, which is all easy to use. Visit http://www.dovepress.com/testimonials.php to read real quotes from published authors. 